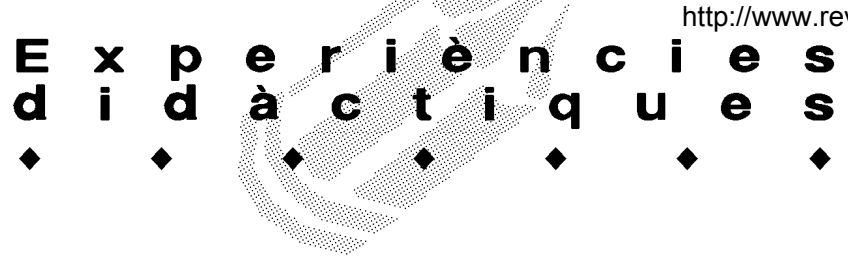

\title{
IDEES SOBRE L'ESTABILITAT A PARVULARI: DESCRIPCIÓ D'UNA EXPERIËNCIA
}

\author{
Agustí Salvat Altés. Àrea de Didàctica de las Ciències Experimentals \\ José Sánchez Real. Escola Universitària de Magisteri. València
}

L'estabilitat i l'equilibri corporal és un dels primers problemes amb els quals s'ha d'enfrontar el cervell dels nens petits, fins que acaba convertint-lo en una rutina. I quan, acadèmicament, s'intenta enquadrar les dades experimentals adquirides amb l'experiència quotidiana, amb els cops i tostorrons corresponents, aquestes no s'aprofiten com una base des de la qual construir els conceptes corresponents.

Bona part dels textos que fins ara s'han fet servir a l'ensenyament primari i secundari estableixen, d'entrada, les distintes classes d'equilibri que es poden donar: estable, inestable i indiferent (sense entrar, en aquest moment, en l'aspecte de si el qualificatiu d'indiferent és encertat des d'un punt de vista dinàmic, ja que és possible que no tingui cap mena de significat dins el marc conceptual de la mecànica newtoniana).

Per iniciar l'estudi d'un tema tan ampli com el de l'equilibri dels cossos, només s'ha fet una exploració amb nens de parvulari (3 i 5 anys) per esbrinar quins són els seus coneixements. Els resultats que a continuació es presenten, obtinguts en proves que en la majoria de casos s'han pensat i modificat a mesura que s'obtenien els resultats, no són definitius, ja que el tema és força complex. És per això que només s'enceta una línia d'investigació i es convida els inquiets a seguir-la i millorar la feina feta.

\section{L'equilibri corporal en moviment}

La iniciació en el tema es realitzà amb 24 nens de parvulari de 4 anys (P4, a partir d'ara), aprofitant el projecte de psicomotricitat que s'està duent a terme al Col-legi de Pràctiques de Tarragona (VIscarro, 1996), amb l'objectiu d'entrar, d'alguna forma, en la qüestió de l'equilibri corporal.

\section{La prova del banc}

La primera part de la sessió es dedicà a veure si els nens tenien equilibri quan caminaven damunt d'un banc

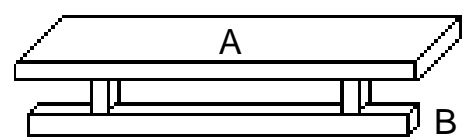

Fig. 1. Banc per analitzar l'equilibri corporal en moviment. de fusta de $2 \mathrm{~m}$ de llarg, $25 \mathrm{~cm}$ d'ample i $35 \mathrm{~cm}$ d'alt (Fig. 1).

Quan els pàrvuls han de caminar pel damunt del banc en posició normal (per la part A de la Fig. 1), resolen la situació de forma satisfactòria. En general, es pot dir que tots tenen el sentit de l'equilibri quan caminen pel banc, llevat de dues nenes -que el passen a quatre grapes-i una altra que va caure. Normalment les nenes passen el banc caminant, ja que els costa més mantenir l'equilibri, mentre que alguns nens ho fan corrent.

Quan el banc s'inverteix; és a dir: la cara A és la que toca a terra i la B és per on han de caminar, la situació es complica. Tots els nens necessiten l'ajuda d'un monitor (donant-los la mà, aguantant-los, etc.). L'únic que ha gosat travessar-lo sol (una nena) ha demanat l'ajuda del monitor quan s'adonat que anava a caure.

LA PROVA DE L'ESCALA I DEL PLA INCLINAT

L'escala usada per analitzar l'equilibri en moviment és d'escuma, folrada amb roba, d'una altura aproximada d'un metre. El pla inclinat, també d'escuma i de roba, té una altura de $80 \mathrm{~cm}$. (Fig. 2).
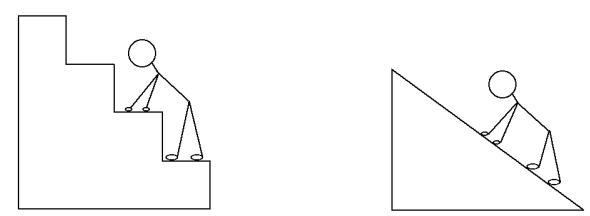

Fig. 2. Escala i pla inclinat per analitzar l'equilibri en moviment.

En general, es pot dir que tots els nens/es pugen a quatre grapes els dos aparells per tal de no perdre l'equilibri. Cal esmentar que la superfície dels dos aparells és inestable, ja que és tova, la qual cosa provoca que es necessiti un major control de la postura i de l'equilibri corporal.

\section{L'equilibri estàtic. Preparació de la prova}

L'experiència es portà a terme amb els nens de parvulari del Col-legi de Pràctiques de Tarragona. Es 


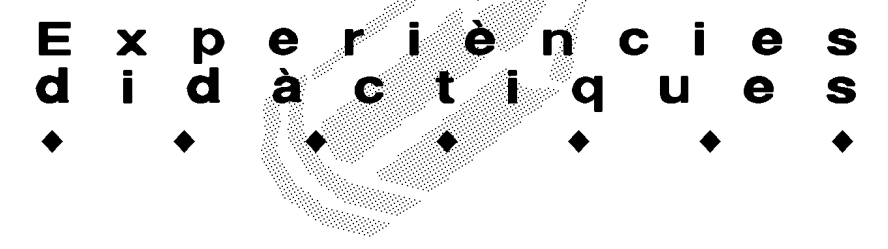

trià, a l'atzar, un dels dos grups de P3 i un altre de P5. D'entrada no es fixà cap calendari concret per passar les proves, però es tingué la precaució de programarles a les primeres hores del dia, quan els nens estan més actius. En principi s'acordà, amb les mestres de parvulari que intervindrien a la prova, que la classe la farien elles, per què es volia que la nostra presència afectés al mínim possible el desenvolupament normal de la classe.

\section{Investigant l'equilibri a P3}

El grup-classe estava constituït per 25 alumnes (dos d'ells amb necessitats educatives especials). Les proves només es passaren a aquells nens que estaven disposats a fer-les. Les qüestions formulades sempre es feren oralment i individualment a cadascun d'ells. L'experiència s'inicià amb una sessió preparatòria perquè s'acostumessin tant a la nostra presència com al material que se'ls presentava. De passada s'observà que les sessions havien de ser curtes, d'uns 15 minuts, aproximadament. Si eren més llargues, es cansaven.

L'EQUILIBRI D'UN COS EN FORMA DE "CASA"

En primer lloc la mestra els explicà un conte on l'intens vent que bufava en una ciutat tombava moltes de les cases on vivia la gent. Tot seguit se'ls mostrà una peça de fusta amb la forma i dimensions indicades a la figura 3, i se'ls plantejaren les qüestions següents:

Pregunta 1: Imagina't que aquesta fusta és una casa. Posa-la de forma que no caigui quan bufa el vent. Explica per què la poses així.

Pregunta 2: Imagina't que aquesta fusta és una casa. Posa-la de forma que caigui quan bufa el vent. Explica per què la poses així.

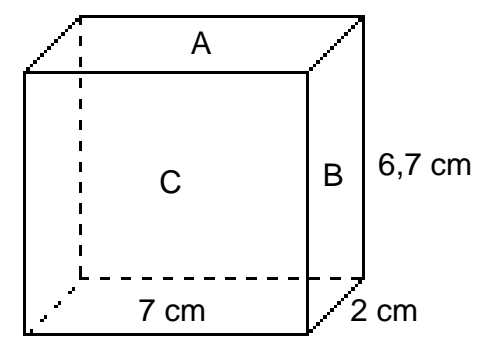

Fig. 3. Investigant l'equilibri d'un cos en forma de "casa".

Las respostes obtingudes van ser, a la primera pregunta: 3 sobre la cara A, 2 sobre la B i 6 sobre la $C$. La segona pregunta va ser contestada així: 4 sobre la A, 6 sobre la B i 1 sobre la $C$.

Malgrat que la meitat d'ells resolen les qüestions plantejades de forma satisfactòria, val a dir que només un parell saben justificar, a la seva manera, la resposta donada a la pregunta 1:

Marina $\mathcal{S}$. (selecciona la cara A): "S'aguanta perquè no cau a l'empènyer" da aixi"

Marina P. (cara B): "S'aguanta perquè l'he posa-

Les respostes a la pregunta 2 no obtenen cap mena de justificació.

En aquest primer assaig es produeix un fet curiós: quasi tots els nens bufen les cases de fusta per veure si cauen. És a dir, entren, espontàniament, en el joc de l'experimentació per tal de comprovar si les prediccions fetes són -o no-correctes.

LA INFLUENCIA DE L'ALTURA D'UN COS SOBRE EL SEU EQUILIBRI

La segona sessió es dedicà a estudiar la possible influència de l'altura d'un cos sobre la seva estabilitat. Per això es feren servir dos tacs de fusta disposats en la posició de la figura 4 (l'A a l'esquerra i el B a la dreta).
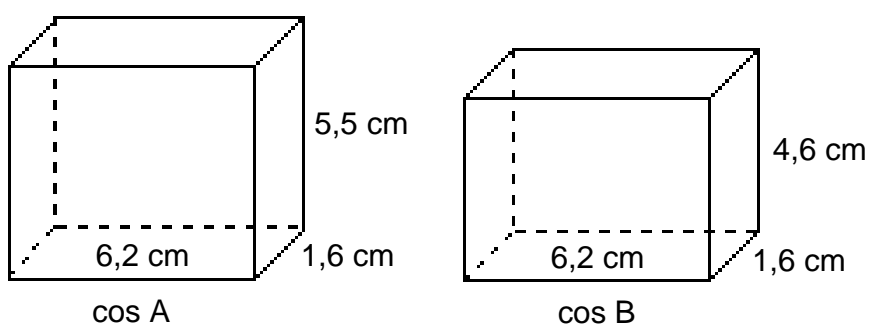

Fig. 4. Cases de fusta emprades en l'estudi de l'estabilitat d'un cos en funció de l'altura.

La pregunta plantejada és: Quan bufi el vent, quina de les dues cases caurà abans?

I la resposta obtinguda: 10 nens el cos A i 4 el B.

S'ha de dir que tots, llevat d'un, realitzen una contrastació experimental per comprovar si la predicció feta és correcta. La majoria fan servir la bufada sobre la casa. Només dos utilitzen el mètode d'empènyer la casa amb el dit fins que caigui. És interessant el cas d'una nena que, després d'haver dit que caurà la $A$, la bufà i en observar que no cau, canvia la resposta a $B$.

Sis dies més tard es repeteix la prova anterior als mateixos nens, amb l'única variant que els cossos emprats es disposen en posició inversa. És a dir, el més alt a la dreta de l'alumne i el més baix, a la seva esquerra (Fig. 5).

Amb aquesta variant de la prova anterior es volia esbrinar si la resposta dels nens està condicionada per la lateralitatde la posició (esquerra-dreta). Les respostes són: 7 d'ells trien el cos A, mentre que els altres 7 agafen el B. Dels 14, 11 mantenen la resposta i 3 la modifiquen. 


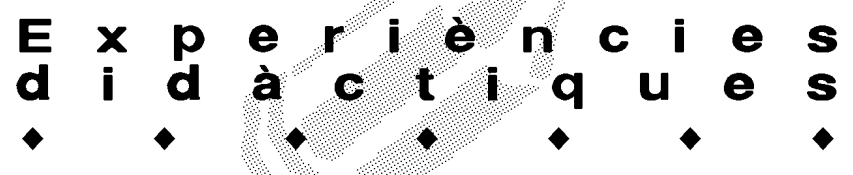

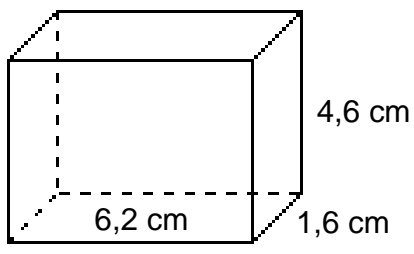

$\cos B$

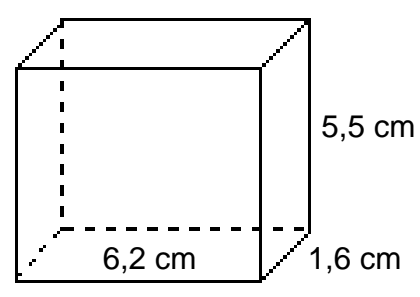

$\cos A$
Fig. 5. Cases de fusta emprades en l'estudi de l'estabilitat d'un cos en funció de l'altura, amb la variant d'intercanviar la posició dels cossos.

És possible que, per als tres que modifiquen la resposta, la posició lateral dels dos cossos (esquerra-dreta) tingui la seva influència quan un cos perd l'equilibri, ja que un diu: "el que es troba a l'esquerra", i un altre afirma: "el de la dreta".

\section{Investigant l'equilibri a P5}

El grup-classe estava format per 25 alumnes (dos d'ells no hi eren els dies que es realitzaren els sondeigs). Les proves només es passaren a aquells nens que estaven disposats a fer-les. Les qüestions formulades sempre es feren oralment $\mathrm{i}$ individualment a cadascun d'ells. L'experiència s'inicià amb una sessió preparatòria perquè s'acostumessin tant a la nostra presència com al material que se'ls presentava. Amb aquest grup-classe es podien fer sessions més llargues que amb els de P3.

LA INFLUĖNCIA DE L'ALTURA D'UN COS SOBRE EL SEU EQUILIBRI

Als alumnes se'ls presentaren els dos objectes de la figura 4 (en el mateix ordre que es troben al dibuix: el més alt a l'esquerra i el més baix, a la dreta) La pregunta és: "Si bufa el vent, quina de les dues cases caurà abans? Explica el perquè.

Dels 16 que responen, tots, a excepció d'un, diuen que la que cauria abans és la més baixa (la B). Pel que fa a la justificació de la resposta, tots, llevat del que ho endevina, argumenten que caurà perquè és més petita.

Atesos els resultats obtinguts, dos dies després es repeteix la mateixa prova, però se'ls fa el suggeriment que bufin sobre les dues cases per comprovar si la predicció que fan és correcta. Els resultats es mostren a la taula 1 , en el mateix ordre en què s'obtenen.

Les dades de la taula 1 són sorprenents, ja que només el número 4 dóna una resposta correcta sense que hagi de fer la corresponent comprovació experimental.

Durant la realització de la prova s'ha detectat que els nens bufen amb poca "força", la qual cosa fa que no caiguin les cases ( 9 casos) i, per tant, que no modifiquin

\begin{tabular}{|c|c|c|c|}
\hline Nen/a & $\begin{array}{l}\text { Predicció } \\
\text { sobre quina } \\
\text { casa caurà } \\
\text { abans }\end{array}$ & $\begin{array}{c}\text { Comprovació } \\
\text { de quina casa } \\
\text { cau al bufar } \\
\text { sobre A i B }\end{array}$ & $\begin{array}{c}\text { Conclusió } \\
\text { sobre quina } \\
\text { casa cau } \\
\text { abans }\end{array}$ \\
\hline 1 & B & A i B & B \\
\hline 2 & B & $A$ i $B$ & $B$ \\
\hline 3 & B & cap & • \\
\hline 4 & A & A & $A$ \\
\hline 5 & B & B & $B$ \\
\hline 6 & B & cap & - \\
\hline 7 & B & cap & • \\
\hline 8 & B & cap & • \\
\hline 9 & B & cap & • \\
\hline 10 & B & cap & • \\
\hline 11 & B & cap & • \\
\hline 12 & B & A (i després B) & A \\
\hline 13 & B & A i B & $B$ \\
\hline 14 & B & A i B & $B$ \\
\hline 15 & B & cap & • \\
\hline 16 & B & cap & • \\
\hline
\end{tabular}

Taula 1. Resultats obtinguts al contrastar experimentalment la predicció feta sobre quina de les cases $A$ i $B$ (de la figura 4) caurà abans. El símbol • indica que no es dóna cap mena de resposta.

la predicció inicial feta.

$\mathrm{Hi}$ ha quatre nens que no saben bufar amb la "força" adequada. Ho fan massa fort... i cauen les dues cases alhora. Com que inicialment havien previst que caigués la $B$, no canvien de resposta. L'únic cas d'aquest estil que és diferent correspon a la nena número 12; com que al bufar primer cau $A$ i després $B$, canvia la resposta a A.

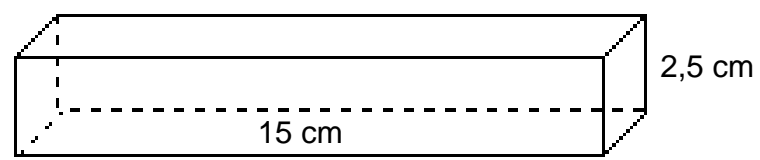

Fig. 6. Fusta emprada per detectar la possible influència de la superfície de suport en l'equilibri. 


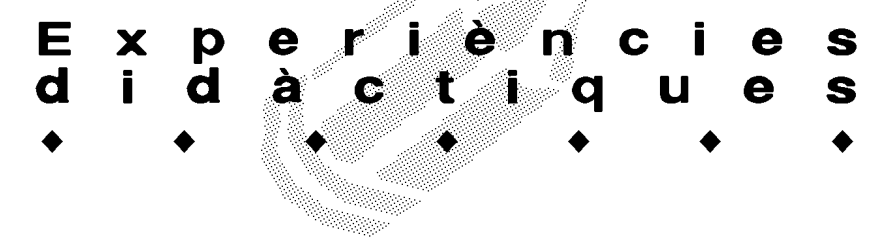

En general, es pot dir que l'exploració feta amb els nens no ha estat satisfactòria, possiblement pel tema del poc control de la intensitat amb la qual bufen. És per

\begin{tabular}{|c|c|c|c|}
\hline $\mathrm{Nen} / \mathrm{a}$ & Plana & Dreta & Justificació \\
\hline - & & $\boldsymbol{\nu}$ & - \\
\hline 11 & & $\boldsymbol{\nu}$ & Així no cauria \\
\hline 2 & & $\boldsymbol{v}$ & Així no cauria \\
\hline 13 & & $\boldsymbol{v}$ & Així no cauria \\
\hline 10 & & $\checkmark$ & - \\
\hline - & & $\boldsymbol{v}$ & - \\
\hline 9 & & $\boldsymbol{\nu}$ & Per què no cauria \\
\hline - & & $\boldsymbol{\nu}$ & Així no cauria \\
\hline - & & $\checkmark$ & - \\
\hline 3 & $\boldsymbol{\sim}$ & & Així no cauria \\
\hline 7 & $\checkmark$ & & Així no cauria \\
\hline • & & $\checkmark$ & És més sencera \\
\hline 6 & & $\boldsymbol{v}$ & No cauria \\
\hline - & & $\boldsymbol{v}$ & No cau \\
\hline 5 & & $\boldsymbol{v}$ & Perquè així no pot caure \\
\hline$\cdot$ & $\checkmark$ & & Perquè no cau \\
\hline 15 & $\checkmark$ & & Perquè no cau \\
\hline 1 & & $\checkmark$ & Així cau més ràpid \\
\hline 16 & $\boldsymbol{\nu}$ & & Perquè no és caiguda \\
\hline 12 & $\checkmark$ & & Perquè està plana \\
\hline 8 & $\checkmark$ & & Perquè cauria més tard \\
\hline 14 & & $\boldsymbol{V}$ & És més petita \\
\hline 4 & $\checkmark$ & $\boldsymbol{\nu}$ & El vertical cau més tard \\
\hline
\end{tabular}

Taula 2. Influència de la superfície de suport sobre l'equilibri d'un $\cos$. Els nens etiquetats amb - no realitzaren la prova a què fa referència la taula 1 . El símbol • a la columna "justificació" significa que no en donen cap. això que, pocs dies després, es fa una nova prova per controlar l'estabilitat en funció de l'altura, sense que hagin de bufar.

LA INFLUĖNCIA DE LA SUPERFICIE DE SUPORT SOBRE L'EQUILIBRI

Per analitzar la possible influència d'aquesta variable s'elegeix una fusta paral-lelepipèdica de secció quadrada $(2,5 \times 2,5 \mathrm{~cm})$ i de $15 \mathrm{~cm}$ de longitud (Fig. 6). La qüestió plantejada als nens és la següent: Com posaries aquesta fusta perquè s'aguanti millor? Per qué?

Les respostes a la pregunta es catalogen, a la taula 2 , en el mateix ordre en què es van obtenir. Els números de la columna "nen/a" són els mateixos que els de la taula 1.

Crida l'atenció el baix nombre de respostes endevinades (8/23), així com les justificacions que majoritàriament es donen: "així no cau". Un cas curiós és el del número 4 , perquè diu que la posició més estable és la dreta, però quan bufa s'adona que la fusta cau. Ràpidament canvia la resposta a plana.

A la segona prova se'ls presenten dues fustes (Fig. 7) i se'ls demana que les posin en la forma que millor s'aguantin i que diguin el motiu de la seva elecció.

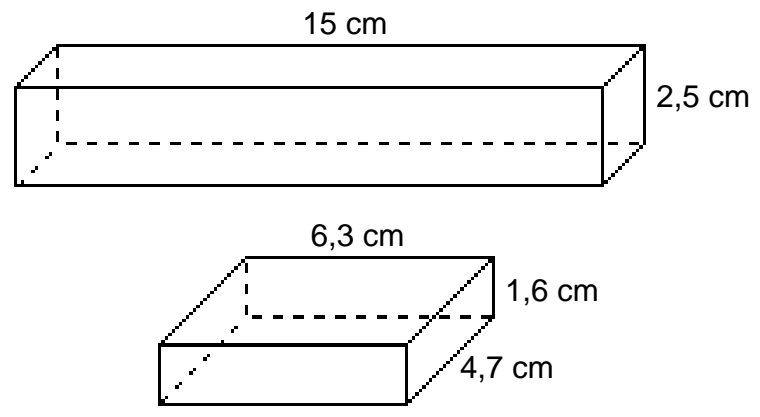

Figura 7. Influència de la superfície de suport sobre l'equilibri d'un cos. Els resultats es donen a la taula 3 .

Els resultats obtinguts es cataloguen a la taula 3. En aquesta taula s'ha col.locat en la columna corresponent a la posició més estable de la fusta la justificació donada per cada nen; així, la seva posició a la taula indica, també, la forma en la qual posen les fustes per tal que s'aguantin millor.

La meitat dels nens enquestats (8/15) resolen la qüestió de forma satisfactòria, ja que seleccionen les posicions més estables de les dues fustes.

Deixant de banda els que diuen: "no cau", "no pot caure", etc. com a justificació, el número 16 argumenta l'estabilitat en base a la posició estirada de les fustes. És a dir: l'estabilitat augmenta quan la base és més gran. El mateix podria dir-se del número 5: "Està estirada". 


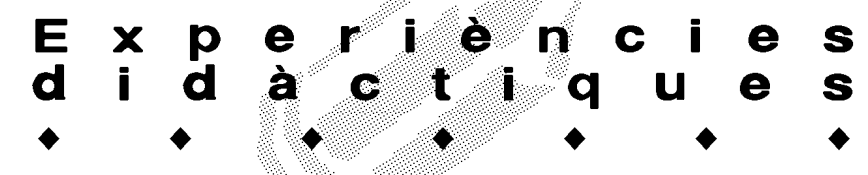

\begin{tabular}{|c|c|c|c|c|c|}
\hline Nen/a & בי & ए & 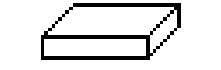 & & \\
\hline 7 & No cau & & No cau & & \\
\hline • & No pot caure & & No pot caure & & \\
\hline - & & No caurà & & No caurà & \\
\hline 11 & & No cau & & & No cau \\
\hline 13 & & No cau & & & No cau \\
\hline 2 & & & & & \\
\hline - & & - & & - & \\
\hline - & No caurà & & No caurà & & \\
\hline • & No cau & & No cau & & \\
\hline 9 & & - & & $\bullet$ & \\
\hline 16 & Està estirada & & Està estirada & & \\
\hline 10 & No caurà & & No caurà & & No caurà \\
\hline 5 & Està plana & & Està plana & & \\
\hline 15 & No caurà & & No caurà & & \\
\hline - & & No caurà & & & No caurà \\
\hline
\end{tabular}

Taula 3. Resultats obtinguts a l'analitzar la superfície d'un cos sobre el seu equilibri. El símbol • a la columna "nen/a" significa que no van realitzar la prova de la taula 1 , mentre que a la resta de la taula vol dir que no donen cap mena de justificació.

\section{Conclusions}

Encara que les conclusions que tot seguit s'indiquen són provisionals, es pot dir que:

a) La meitat dels nens de P3 consideren que l'estabilitat d'un cos en forma de casa augmenta quan la base de sustentació és gran, i disminueix quan aquesta base minva.

b) La majoria dels nens de $\mathrm{P} 3$ entren, espontàniament, en el joc de la comprovació experimental per veure si les seves prediccions són correctes. Aquest aspecte és important de cara a afavorir l'aprenentatge científic en edats més avançades.

c) Entre la meitat i la tercera part dels nens de P5 saben seleccionar la posició més estable d'un objecte paral-lelepipèdic, però no saben justificar el perquè d'aquesta estabilitat.

\section{Agraïments}

Cal fer constar la col-laboració i bona disposició que, en tot moment, han tingut les mestres de parvulari del CEIP de Pràctiques de Tarragona, Lluïsa Picó i Montse Fortuny, ja que sense la seva valuosa ajuda aquest treball mai no hauria vist la llum.

\section{Referències bibliogràfiques}

VISCARRO, I. i FUGUET, J. Treballem la psicomotricitat a parvulari. «Comunicació Educativa», 9 (1996) 43-46. 